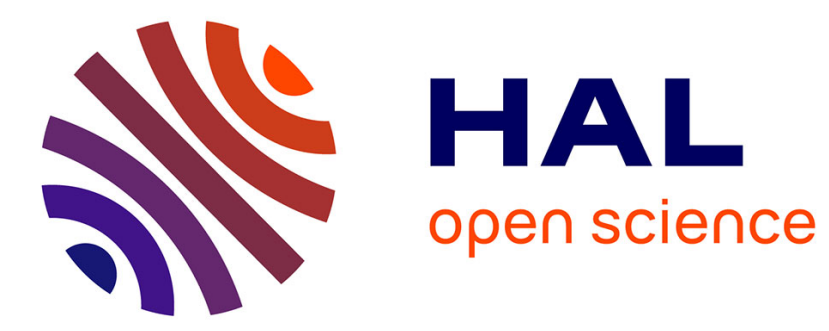

\title{
A propos d'une révision du vocabulaire forestier français
}

François Bergeot

\section{To cite this version:}

François Bergeot. A propos d'une révision du vocabulaire forestier français. 2003, pp.380. 10.4267/2042/5203 . hal-03449269

\section{HAL Id: hal-03449269 \\ https://hal.science/hal-03449269}

Submitted on 25 Nov 2021

HAL is a multi-disciplinary open access archive for the deposit and dissemination of scientific research documents, whether they are published or not. The documents may come from teaching and research institutions in France or abroad, or from public or private research centers.
L'archive ouverte pluridisciplinaire HAL, est destinée au dépôt et à la diffusion de documents scientifiques de niveau recherche, publiés ou non, émanant des établissements d'enseignement et de recherche français ou étrangers, des laboratoires publics ou privés. 


\section{LIBRE EKPRESSION}

\section{À PROPOS D'UNE RÉVISION DU VOCABULAIRE FORESTIER FRANÇAIS}

Dans son article intitulé "Plaidoyer pour une révision précise et actualisée du vocabulaire forestier français dans le cadre européen et international", paru dans le numéro 1-2003 de la Revue forestière française, $\mathrm{M}^{\mathrm{me}}$ Marie-Stella Duchiron évoque le travail fait dans ce domaine par des " groupes semi-officiels » auxquels des "initiatives locales " pourraient être étrangères.

L'Inventaire forestier national (IFN), dans sa forme actuelle établissement public de l'État chargé de la mission d'inventaire prévue par l'article L. 521-1 du Code forestier, fait depuis plusieurs années un travail de rénovation de sa nomenclature.

Elle est partiellement accessible sur le Web (http://www.ifn.fr/pages/fr/bd/nomenclature.htm).

Si cette nomenclature est orientée vers l'inventaire des forêts, tout ce qui se rapporte à la description des arbres et des peuplements concerne directement les utilisateurs des résultats d'inventaire et doit être compris par eux de la même manière que par ceux qui ont produit ces résultats.

Il serait donc heureux que l'IFN soit associé au travail proposé par $M^{\text {me }}$ Duchiron, si les autorités forestières de notre pays donnent suite à son projet.

François BERGEOT

Chef de l'Échelon interrégional de Montpellier INVENTAIRE FORESTIER NATIONAL

Place des Arcades

BP 1001

Maurin

F-34972 LATTES CEDEX

(fbergeot@ifn.fr) 